\title{
Inmóvil bajo su pecho como una adversaria desgraciada. Pablo Neruda, violador, y la violación de mujeres estatuas como tema recurrente en su poesía amorosa
}

Francisco Leal

Colorado State University

Una mañana, decidido a todo, la tomé fuertemente de la muñeca

y la miré cara a cara. No había idioma alguno en que pudiera hablarle.

Se dejó conducir por mí sin una sonrisa y pronto estuvo desnuda sobre mi cama. Su delgadísima cintura, sus plenas caderas,

las desbordantes copas de sus senos,

la hacían igual a las milenarias esculturas del sur de la India. El encuentro fue el de un hombre con una estatua.

Pablo Neruda. Confieso que he vivido.

Yo me encomiendo a su estrella morena, a su calidez de piel, e inmóvil bajo mi pecho como un adversario desgraciado, de miembros demasiado espesos y débiles, de ondulación indefensa: o bien girando sobre sí misma como una rueda pálida, dividida de aspas y dedos

Pablo Neruda. "La noche del soldado".

\section{Violación y poesía nerudiana}

Pablo Neruda (1907-1973) es uno de los poetas de mayor renombre de la literatura mundial. Y también un violador confeso. Atacó sexualmente a una de sus sirvientas "de la raza tamil, de la casta de los parias" en Colombo, Singapur (Confieso, 131). La violación de Neruda, relatada única y tardíamente en sus memorias, Confieso que he vivido, publicadas tras la muerte del poeta, será el foco de este trabajo, que no es un juicio moral al poeta, ni un ajuste de cuentas con la crítica nerudiana, que ha desatendido este hecho, tanto en sus biografías como en el análisis de su poesía. Tampoco es un intento de censura literaria. Al enfocarme en ese ataque sexual del poeta busco exclusivamente revisar la celebrada poesía amorosa de Neruda y las maneras en que ha sido consumida masivamente, pero tomando en consideración la violencia sexual como una temática discursiva permanente y nada excepcional en su celebrada poesía amorosa. Para esa finalidad 
sigo a Virginie Despentes y su libro Teoría King Kong donde denuncia que la violación "está omnipresente en el arte, desde la antigüedad", pues "su representación en los textos, la escultura, la pintura es una constante a través de los siglos" (42). La violación, por tanto, afirma Despentes, no es "extraordinaria y periférica", algo "fuera de la sexualidad, evitable", como "si solo concerniese a poca gente, agresores y víctimas, como si fuera una situación excepcional, que no dice nada del resto" (42). Más bien, "al contrario", continúa Despentes, la violación "está en el centro, en el corazón, base de nuestras sexualidades (42). Siguiendo a Despentes, considero que la violación que confiesa Neruda en sus memorias no es un dato periférico de su vida, imposible de rastrear en la obra del poeta, sino que se destaca como un dato que subyace "en el corazón" de la poesía más celebrada de Neruda. En este trabajo me centraré en lo que nos informa el poeta sobre la violación contra su sirvienta en su tardía confesión, en el sintomático silencio de la crítica nerudiana respecto de esta violación, y en las maneras en que elementos discursivos de esa violación se reproducen tanto en el poema "La noche del soldado" de Residencia en la Tierra como en sus colecciones de estatuas de mujeres, ambos ejemplos de las réplicas de la retórica de la violación en la poética de Neruda.

La obra de Neruda es especialmente diversa, en temas y en formas. Sus "obras completas", asegura Hernán Loyola, editor de una de ellas, "suman alrededor de 6.000 páginas" (Neruda, 9) Insinuar, por tanto, que la violación es el sustento exclusivo de la temática amorosa de la poesía de Neruda, es una errónea simplificación. También es una simplificación incorporar, aunque sea conflictivamente, esta violación solo como un nefasto suceso de la vida del poeta, repudiable, como otros del poeta en Asia, pero totalmente ajeno a su poesía. Prefiero destacar la violación de Neruda como un elemento indigerible y permanente, como el fantasma que recorre la obra de Neruda, como el dato espectral en la vida y obra de Neruda que no deja de distorsionar la imagen romantizada y más consumible del poeta.

La exhaustiva y abundante crítica nerudiana ha resaltado con detalles casi todas las relaciones sentimentales y sexuales de Neruda, con nombres propios y pormenores, y ha utilizado los detalles de estas relaciones como plataforma de lectura e interpretación de sus poemas. "Cuando me muera van a publicar hasta mis calcetines", temía Neruda (Cuadernos de Temuco, 5). Su temor fue una profecía, pues cientos de inéditos poemas, discursos políticos, crónicas periodísticas, epistolarios, biografías, entre otros muchos documentos del poeta, han visto la luz tras su muerte. Materiales y documentos en los que los especialistas nerudianos se han detenido atentamente para completar la biografía del poeta y encontrar nuevos datos acerca de su poesía. Sin embargo, la minuciosa crítica nerudiana no se ha detenido en el ataque sexual a una de sus sirvientas declarado por el poeta, pese a la explícita y pública confesión por parte de Neruda. Esta violación ha sido simultáneamente silenciada de la biografía de Neruda y también aislada como elemento de su poesía. La crítica nerudiana suele ser biográfica: resalta datos conocidos o desconocidos del poeta como referente principal para interpretar su poesía. Entre otras razones porque la poesía de Neruda es "desfachatadamente egocéntrica", como afirma Loyola (Neruda, 10). Incluso en el terreno de la crítica biográfica, este ensayo es una contribución, ya que resalta un 
aspecto desatendido de la vida del poeta y, por lo mismo, destaca un posible nuevo elemento -distorsionador, en este caso- para la interpretación de su poesía. Pero este trabajo es también una lectura analítica, pues se centra la violación como un elemento clave de la poesía amorosa de Neruda, y también un elemento que interroga la imagen romántica, comunitaria y consumible del poeta.

\section{Neruda y sus sirvientes asiáticos}

El deplorable trato de Neruda a las mujeres, tanto en su vida como en su obra, ha sido revisado por la crítica nerudiana más reciente. Pero muy poco se ha comentado respecto del despreciable trato que Neruda dio a sus sirvientes. La víctima de la violación que confiesa el poeta fue precisamente una sirvienta, ejemplo brutal pero no exclusivo de la abusiva relación del poeta con sus sirvientes en Asia. Esta manifiesta violencia contra sus sirvientes pone en tela de juicio tanto la imagen de "poeta del pueblo" con que se suele consumir a Neruda y su poesía, como también la idea de la "desolación asiática" con que Neruda y sus exégetas han descrito la experiencia del poeta en continente asiático, justificándola como el trasfondo principal del poemario que escribe en esa estancia: Residencia en la tierra (1933) ${ }^{1}$. Neruda siempre tuvo sirvientes: en Asia, en Europa, en las Américas, y no siempre tuvo con sus empleados la simpatía que retrata hollywoodensemente la exitosa película Il Postino (1994), ejemplo cinematográfico del Neruda más consumible². Mucho menos en su estancia asiática.

Neruda trabajó como empleado diplomático del Estado chileno entre 1928 a 1932 en Rangún, Birmania, Sri Lanka, Java, Singapur, Colombo y Batavia. Los años "desolados" de Neruda en Asia están muy bien documentados y esas experiencias relucen en varios poemas de Residencia: fumó opio ("Establecimientos nocturnos"), abandonó a su hija hidrocéfala ("Enfermedades en mi casa"), a su(s) amante(s) asiática(s) ("Tango del viudo"), y no dejó de asombrarse por las costumbres de Asia ("Entierro en el Este"). Sobre estos temas, en mayor o menor medida, se ha detenido la crítica nerudiana ${ }^{3}$. Sin embargo, habitualmente se mencionan estos hechos enmarcados en lo que el mismo Neruda instaló como su sello de lectura o consumo: su experiencia en Asia como una experiencia juvenil y desolada. Pero esa "desolación" tiene sus aristas, pues pese a todas las penurias de las que se queja el poeta, en

\footnotetext{
1 Adam Feinstein titula estos años del poeta en su biografía como "Desolación asiática" ("Asian Desolation" 51). El mismo Neruda en Confieso que he vivido denomina estos años como "La soledad luminosa" y su principal biógrafo, Volodia Teitelboim, como "Agonía y creación" (X).

2 Como indica María Luisa Fischer en Neruda: construcción y legados de una figura cultural, "hacia mediados de la década de los noventa, y debido al éxito del film Il postino (1995), dirigido por Michael Radford, emerge una imagen nerudiana al puro estilo holywoodense" (70). 3 Sobre el abandono a su hija hidrocéfala, que aparece poetizado en "Enfermedades en mi casa", ver Bernardo Reyes, El enigma de Malva Marina. Existen varios trabajos acerca de las amantes asiáticas de Neruda, encarnadas en el nombre de "Josie Bliss". Ver Kanton: "Chasing Josie Bliss". Sobre el asombro de exotista del poeta en oriente, reflejado en el poema "Entierro en el Este", ver "Un licor extremo", de Silvia Nagy-Zekmy. Sobre el opio y la descripción de Neruda sobre su consumo y repercusiones en su poesía, ver Francisco Leal: "Pablo Neruda y el opio (del pueblo)" y "Quise entonces fumar: El opio en César Vallejo y Pablo Neruda".
} 
su estancia en Asia, por ejemplo, era servido por "una cocinera javanesa", y también por "un boy, también javanés" que "servía a la mesa y limpiaba mi ropa. Allí terminé Residencia en la tierra", declara el poeta (Confieso, 145). El poeta finaliza uno de sus libros más importantes rodeado de sirvientes, pero quejándose de soledad. La "verdadera soledad la conocí en aquellos días y años de Wellawatha", declara Neruda, pues no tenía "más compañía que una mesa y dos sillas, mi trabajo, mi perro, mi mangosta y el boy que me servía y regresaba a su aldea por la noche" (Confieso, 123). Pero este sirviente "no era propiamente compañía", ya que "su condición de servidor oriental lo obligaba a ser más silencioso que una sombra" (123). Al silencioso sirviente, que "parecía que se le había olvidado el lenguaje", no "era preciso ordenarle nada, pues todo lo tenía listo: mi comida en la mesa, mi ropa acabada de planchar, la botella de whisky en la veranda" (Confieso 124). Neruda se cansaba "de ser hombre", como precisa en su poema "Walking around" de Residencia en la tierra, mientras una mujer le servía y cocinaba, otro limpiaba y planchaba su ropa, rellenaba su whisky, y otros le hacían las compras. "Estoy solo: cada diez minutos viene mi sirviente, Ratnaigh, viene cada diez minutos a rellenar mi vaso", le señala a Eandi sobre su desventurada vida de diplomático en Asia (Itinerario, 53). "Pablo duerme, se tira una caña de opio y despierta justamente para cumplir los deberes oficiales", le comenta Álvaro Hinojoza al mismo Eandi (Itinerario, 53).

Neruda también se identifica culturalmente con los colonizadores blancos en Asia y se distingue radicalmente de los nativos del subcontinente indio: "Todos los sirvientes roban en la India", reclama Neruda, pero "no se puede prescindir de ellos porque es mal mirado que la gente blanca haga cualquier cosa por sí misma", ya que "el blanco no debe comprar nada en el mercado o en la calle, de otra manera los nativos perderían su respeto" (Citado de Loyola. Neruda, 389). Neruda, que no era blanco, se identificaba con los colonos no solo racialmente sino también por medio de su deplorable comportamiento colonialista, como veremos. En estas mismas líneas, Neruda le comenta a su hermana sobre Asia: "Aquí todas las mujeres son negras, no hay cuidado, no me casaré (Cartas a Laura, 35). Se casará luego con una colona blanca: Maria Antonieta Hagenaar. Y antes violará a una sirvienta nativa. Las constantes impresiones negativas de Neruda hacia Asia y sus habitantes, como también su cercana identificación con los colonizadores, me hacen desconfiar del repetido perfil desolado del poeta en ese continente. Neruda no fue una víctima en Asia. Todo lo contrario. En ese despótico contexto, y no en el de un poeta desolado en Asia, Neruda viola a una de sus sirvientas.

\section{Neruda violador}

La breve declaración de la violación aparece en las memorias de Neruda, Confieso que he vivido. Esta confesión se impregna de elementos poéticos nerudianos -exotismo, erotismo, silencios, etc.- y aparece yuxtapuesta entre otras escenas sexuales del poeta, enmarcando así la violación de su sirvienta dentro del contexto del exotismo sexual de un joven Neruda en Asia. Antes de confesar su violación, Neruda recuerda que en Colombo "Amigas de varios colores pasaban por mi cama de campaña sin dejar más historia que el relámpago físico", pues su cuerpo "era una hoguera solitaria encendida noche 
y día en aquella costa tropical" (Confieso, 44). Así, "muchachas morenas y doradas, con sangre de boers, de ingleses, de dravidios. Se acostaban conmigo deportiva y desinteresadamente" (Confieso, 133). Estas exuberantes escenas sexuales -una amiga le confiesa que "había fornicado con catorce" colonos en una sola noche (Confieso, 133)- anteceden narrativamente a la violación que luego confiesa, y sirven discursivamente para disimular su singularidad y presentarla como una más de las muchísimas exuberancias sexuales de Neruda en Asia.

El relato de la violación comienza con el momento en que Neruda conoce a su víctima: una sirvienta que se encarga de limpiar el retrete del poeta: "El cubo amanecía limpio cada día sin que yo me diera cuenta de cómo desaparecía su contenido" (133), precisa. Al descubrir la identidad de la persona que limpiaba sus excrementos, Neruda continúa su confesión exotizando a su víctima, a quien presenta como "una oscura estatua" (133) y la fragmenta en objetos, en falsas joyas. Su víctima iba "vestida con un sari rojo y dorado, de la tela más burda", y en "los pies descalzos llevaba pesadas ajorcas. A cada lado de la nariz le brillaban dos puntitos rojos. Serían vidrios ordinarios, pero en ella parecían rubíes" (133). Y continúa:

Una mañana me había levantado más temprano que de costumbre. Me quedé asombrado mirando lo que pasaba. Entró por el fondo de la casa, como una estatua oscura que caminara, la mujer más bella que había visto hasta entonces en Ceilán, de la raza tamil, de la casta de los parias (133).

La sirvienta ignora al poeta, pues "se dirigió con paso solemne hacia el retrete, sin mirarme siquiera, sin darse por aludida de mi existencia, y desapareció con el sórdido receptáculo sobre la cabeza, alejándose con su paso de diosa" (132). Neruda endiosa a su víctima, romantizándolo, para justificar su ataque, y también la animaliza: "Era tan bella que a pesar de su humilde oficio me dejó preocupado", comenta, "como si se tratara de un animal huraño, llegado de la jungla", que "pertenecía a otra existencia, a un mundo separado" (133). Neruda relata su violación como una cacería, es decir como un ataque premeditado. Su víctima no es azarosa ni su violación solo el arrebato de "una mañana, decidido a todo", pues antes de atacar a su sirvienta, el poeta la acosa repetidas veces. Le deja en "su camino algún regalo, seda o fruta", pero "ella pasaba sin oír ni mirar" (133). Neruda insiste, pues "aquel trayecto miserable había sido convertido por su oscura belleza en la obligatoria ceremonia de una reina indiferente" (134). La violación sucede cuando la sirvienta no se deja seducir por los trucos acosadores del poeta, quien finalmente decide atacarla:

la tomé fuertemente de la muñeca y la miré cara a cara. No había idioma alguno en que pudiera hablarle. Se dejó conducir por mí sin una sonrisa y pronto estuvo desnuda sobre mi cama. Su delgadísima cintura, sus plenas caderas, las desbordantes copas de sus senos, la hacían igual a las milenarias esculturas del sur de la India. El encuentro fue el de un hombre con una estatua (Confieso, 134-5). 
Lo que Neruda narra con muchos silencios como uno más de sus múltiples encuentros sexuales en Asia, es una forzada, violenta y premeditada violación a una de sus sirvientas. Violencia que Neruda omite en su relato: ¿Cómo condujo a su víctima hasta el dormitorio? ¿Cómo arrancó sus vestidos? Nada sabemos. Sabemos, sin embargo, que durante el ataque la sirvienta "permaneció todo el tiempo con sus ojos abiertos, impasible" (135), según cuenta Neruda. "Hacía bien en despreciarme", recuerda acertadamente el poeta. Esta es toda la información que tenemos sobre la sirvienta atacada y la violación de Neruda, que termina su confesión con un elocuente arrepentimiento: "No se repitió la experiencia" (135). El dudoso arrepentimiento final del poeta ha servido para que este episodio haya sido desatendido como un dato significativo de su biografía y sobre todo como un acto disociado completamente de su obra. Sin embargo, el hecho de que Neruda resalte en un detallado relato confesional esta violación con especial atención al final de su vida, más de treinta años después del ataque que mantuvo en secreto (al menos inédito), y que afirme que fue una experiencia que no se repitió, prueban que fue un hecho, a lo menos, singular en la vida del poeta.

\section{Violación y silencio}

De Pablo Neruda se han comentado incontables aspectos de su vida. Llegaron "los investigadores, los espías, los violadores de alcobas ya cerradas, los policías de amores retrospectivos", que temía Teitelboim (Neruda 87). Sin embargo, la explícita violación confesada por el poeta en sus memorias ha permanecido significativamente desatendida. Slavoj Zizek, filósofo de Eslovenia, ha puesto mayor atención sobre esto hecho que los más documentados especialistas nerudianos. En su libro Living in the End Times, Zizek cita y se detiene en la escena de violación confesada por Neruda y advierte que "este pasaje es notable" (25), por "obvias razones", como "la desvergonzada historia de una violación" de un célebre poeta, "con los sucios detalles" de esta violación "discretamente ignorados", entre otros elementos. Sin embargo, la crítica nerudiana no ha atendido este pasaje "notable" de la biografía de Neruda, pese a conocer los detalles de esta violación y citar la confesión de Neruda de este ataque en sus exhaustivos trabajos.

Hernán Loyola en Neruda. La biografía literaria (2006), reclama que "denunciar o ventilar presuntos delitos morales de Neruda" es "un deporte nacional que no se practica con igual entusiasmo respecto a ningún otro escritor chileno" (11). Neruda, comenta Loyola, "no fue un santo, ni mucho menos, pero fue un hombre íntegro" (12). Esa integridad de Neruda que resalta Loyola en su libro solo es posible ocultando su violación, mezclándola y confundiéndola con otras exuberancias del joven poeta en Asia. "Pablo" es el nombre que da el biógrafo a ese Neruda, "para subrayar su condición juvenil" (Neruda, 12). Loyola asegura que "como otros episodios de la memoria sexual del poeta", la violación confesada en sus memorias había sido omitida en referencias y autobiografías anteriores y solo escribe sobre ella "durante la última fase de su vida" (Neruda, 396). Pero, sobre todo, Loyola enmarca el episodio de la violación bajo el significativo subtítulo "Aquellas vidas". Es decir, para Loyola, lo que hizo Neruda (o "Pablo") en Asia pertenece a aquellas lejanas vidas del joven poeta en ese continente. En el "campo sexual", ahonda Loyola, Neruda, "insiste sobre el tema de la soledad -erótica, ante 
todo- que vive en la gran Isla" de Wellawarra, donde acomete la violación (396). A diferencia de Colombo, en Wellawarra, Neruda "no encuentra ninguna mujer que le interese" o "él no logró interesar a ninguna", indica el crítico, desestimando la sirvienta violada en la isla (395). Loyola no se equivoca al destacar la importancia de la sexualidad de Neruda en Wellawarra. Pero hace todavía más llamativa la elocuente desatención con que trata la violación confesada por el poeta en esa isla.

Loyola transcribe en su biografía casi íntegramente el pasaje donde Neruda confiesa su ataque, pero no habla de violación en ningún momento. Tampoco hay referencias a esta confesión como un ataque sexual por parte del poeta. El biógrafo destaca la importancia de la tardía confesión de Neruda, pues era un "trozo inédito" en la vida del poeta, y se pregunta acerca de las posibles razones que tuvo del poeta para aislar y silenciar esta violación entre sus recuerdos, y para traerla a "la superficie textual solo en época tardía" (395). Pero pese a copiar este pasaje de las memorias en su biografía literaria y destacar las diferencias entre los silencios de las primeras crónicas del poeta al llegar a Asia -donde no se centra en su sexualidad- y sus tardías confesiones del poeta, donde las revisa crudamente, Loyola, como otros críticos, no habla de violación. "Pasan los rostros -Patsy, Ellen, Artiyha- (...) efímeras mujeres", dice Neruda en el poema "Territorios", citado por Loyola (395). Pero la sirvienta violada no ha sido singularizada, ni entre muchísimas "efímeras mujeres" de Neruda que han recibido, por el contrario, especial atención de Loyola y de otros especialistas. En ese significativo descuido, Loyola no está solo.

Volodia Teitelboim en su biografía titulada Neruda, señala que el poeta en Asia "se agarra a la vida. Lo atan a ella las mujeres", pero "esto de ir de cama en cama, de niña en niña, nativa, mulata o inglesa, lo dañarían por dentro y lo satura de hastió" (144). Pero Teitelboim no hace referencia en ningún momento a la violación del poeta. Adam Feinstein, por su parte, en su biografía, Pablo Neruda: A Passion for Life, a diferencia de Teitelboim, sí se detiene en la confesión de violación de Neruda y cita casi íntegramente el pasaje de este ataque de sus memorias. Sin embargo, la sirvienta violada por Neruda no es una víctima de la voracidad sexual del poeta, sino "la mujer más bella que había visto en todo su tiempo en Ceilán" (69). Ni siquiera esa destacada belleza exótica de la sirvienta violada conduce al crítico a enfatizar este ataque, sino que lo presenta como otro acto sexual del desolado Neruda asiático y a la sirvienta, como una más de las varias mujeres con las que fornicó Neruda, solo para incrementar su "aburrimiento y culpa" (Pablo Neruda, 69). Feinstein, tampoco habla de violación.

Edmundo Olivares, por su parte, también cita esta confesión de Neruda en su extensivo trabajo sobre el poeta en Asia: Pablo Neruda: Los caminos de oriente. Pero tampoco habla de violación. Tras citar el ataque confesado por Neruda, y destacarlo como "uno de los episodios de atracción sexual más complejo, patético y a la vez poético" del poeta, pasa, sin comentarios, a "otro orden de cosas" (201). Pero no sin antes celebrar la singularidad de Neruda en la premeditada elección de la víctima de su violación, pues pese a que la sirvienta limpiaba los excusados del poeta, razón por la cual "otro hombre cualquiera, extranjero o nativo, pese a su inicial admiración 
le hubiera dado la espalada con disgusto", no fue el caso de Neruda (202). Solo puedo imaginar que la seducción retórica con que Neruda confiesa este ataque, inseparable de su retórica amorosa, es lo que lleva a Olivares a afirmar que la violación de Neruda a su sirvienta es un momento "patético a la vez que poético" (202). Si Olivares, un atento estudioso de Neruda, considera este relato de violación como algo "poético" no es solo porque Neruda se sirve de su virtuosismo lingüístico para confesar su violación, sino que prueba también que la retórica de esa violación recorre profundamente la escritura nerudiana.

Hernán Loyola, Cristián Olivares, Adam Feinstein, entre otros importantes especialistas nerudianos, no se refieren al ataque sexual de Neruda como una violación, pese a que son especialmente prolijos en resaltar datos biográficos del poeta como herramientas interpretativas de sus poemas. Este descuido no se debe a un intento de ocultar secretos de la vida de Neruda: ha sido el propio Neruda el que ha relatado su violación, en su autobiografía más oficial, y ha sido citada repetidas veces por los especialistas. La violación no es un secreto del poeta. Pero celebrar la poesía erótica de un violador resulta problemático. Solo ignorando la violación se puede celebrar el romántico erotismo de Neruda, consumido masivamente.

Una refrescante excepción respecto del menosprecio general de la crítica nerudiana respecto de la violación del poeta la brinda la reciente biografía de Mark Eisner: Neruda. The Poet's Calling (2018), donde el biógrafo pone en duda la victimización de Neruda en Asia. En el continente indio, el poeta estaba "cómodo en el rol de agresor -incluso depredador" (177), comenta Eisner, siendo el único biógrafo hasta ahora que comenta el ataque de la sirvienta como una violación - "rape" (178)- acometida por el poeta con sentimientos "de superioridad" racial, cultural y de género (178). Pese a que no existe evidencia de que Neruda haya "cometido otro asalto de esta naturaleza", Eisner destaca que en su confesión "describe su ejercicio de poder y privilegio con poca vergüenza" (177), pues "incluso tarde en su vida [Neruda], no reconocería la inhumanidad de sus acciones. No hay verdadero arrepentimiento, ni explicación para ese comportamiento" (178). El paso que no da el novedoso trabajo de Eisner es percibir resonancias de este relato de violación en la poesía amorosa de Neruda. Ese paso es el que intentaremos en la siguiente sección.

\section{Neruda y la violación}

Pese a no hablar de violación en la confesión de Neruda, Loyola sí se detiene especialmente en la significativa imagen poética de enterrar un cuchillo que aparece en el en poema "Tango del viudo", escrito poco antes del ataque del poeta a su sirvienta. Loyola destaca este ataque como una imagen cargada con el simbolismo de una "penetración, incluso de estupro o violación en este caso", pues el poeta-narrador está "privado del consentimiento de la partner" (376). Tema en el que, según Loyola, insiste el poeta, años después, en "Las alturas de Machu Pichu", donde el poeta declama, citado por Loyola: "como una espada envuelta en meteoros/ hundí la mano turbulenta y dulce/ en lo más genial de lo terrestre (Neruda, 376). Énfasis en la cita original de Loyola, y énfasis, por lo tanto, en la recurrente tematización de la violación 
en la poesía de Neruda que destaca el biógrafo. La violación es también uno de los temas centrales en la sección "Los conquistadores" de Canto general, poema en el que Neruda iguala la conquista europea de las Américas a un ataque sexual, pues como precisa Teitelboim, ahí la conquista aparece representada como "la violación de la madre, transferido en símbolo telúrico" (Neruda, 27). Es decir, siguiendo a Loyola y Teitelboim, la violación recorre temáticamente la poesía de Neruda, "está en su corazón" diría Despentes.

El poema "La noche del soldado" es otro ejemplo de las resonancias del discurso de la violación en la poesía de Neruda y que me permite afirmar que la violencia sexual es un tema constante en su escritura. Loyola precisa que "La noche del soldado" fue escrito en Rangún (Birmania), entre mayo y octubre de 1928 (Residencia, 14). La violación de Neruda contra su sirvienta sucedió en Colombo entre 1929 y 1931. La violación, por tanto, sucede después de la escritura del poema. Sin embargo, aunque no pueda ser un poema sobre ataque sexual que confesó el poeta contra su sirvienta, el desfase temporal entre el poema y la violación alerta de una clara predisposición exotista, misógina y orientalista por parte de Neruda. Como indica Patricia Vilches, Neruda, al describir a la mujer de "La noche del soldado", no está solo evocando un recuerdo de alguna mujer del Este, sino que su representación de las mujeres de ese continente "se define a través de la orientalización de un hombre del Oeste sobre la mujer del Este" ("La más bella de Mandalay", 213). La falta de singularización de las mujeres de Neruda en Asia, sin nombre (como la sirvienta violada), con muchos nombres ("Patsy, Ellen, Artiyha", como indica en el poema "Territorios" antes citado) o con un nombre para muchas amantes ("Josie Bliss", como veremos), es una prueba de la violencia discursiva de las ficciones orientalistas del poeta.

El orientalismo de Neruda en "La noche del soldado" ha sido un tema trabajado por las estudiosas Roanne Kanton, en su artículo "Chasing Your (Josie) Bliss", Silvia Nagy-Zekmi, en "Un licor extremo", además de los trabajos de Vilches y Eisner antes citados. Estas especialistas, sin embargo, no se han detenido en las similitudes de las representaciones orientalistas de los cuerpos asiáticos que se repiten tanto en "La noche del soldado" como en el relato confesional de la violación de Neruda. En su confesión, Neruda presenta exóticamente a su víctima antes de atacarla. Esa fantasía depredadora y exotista estaba en marcha antes de la violación, poéticamente. Si en el relato de la violación, Neruda describe a su sirvienta como estatua y la fragmenta en objetos exóticos: anillos, brazaletes, collares, etc., esos mismos objetos y objetivaciones se repiten en "La noche del soldado":

Ellas llevan anillos en cada dedo del pie, y brazaletes, y ajorcas en los tobillos, y además, collares de color, collares que retiro y examino, porque yo quiero sorprenderme ante un cuerpo ininterrumpido y compacto, y no mitigar mi beso (Residencia en la tierra, 147-8).

En "La noche del soldado" los exóticos cuerpos de mujeres aparecen igualmente representados como "nuevas estatuas", "de ondulación indefensa"; cuerpos que son fragmentados en "una rueda pálida, dividida de aspas y dedos", cuerpos salvajes, "como una estrella en desorden", dispuestos como 
objetos o "lámparas de luz" para satisfacer la "sed masculina" del hablante que trepa "por su ser desnudo". El cuerpo transformado en exótica estatua de "La noche del soldado", como también el de sirvienta que relata en su violación, representada como exótica estatua, es un cuerpo "inmóvil" "como un adversario desgraciado" bajo el "pecho" del poeta:

Yo peso con mis brazos cada nueva estatua, y bebo su remedio vivo con sed masculina y en silencio. Tendido, mirando desde abajo la fugitiva criatura, trepando por su ser desnudo hasta su sonrisa (148).

Y luego:

Yo me encomiendo a su estrella morena, a su calidez de piel, e inmóvil bajo mi pecho como un adversario desgraciado, de miembros demasiado espesos y débiles, de ondulación indefensa: o bien girando sobre sí misma como una rueda pálida, dividida de aspas y dedos, rápida, profunda, circular, como una estrella en desorden (148).

"La noche del soldado" fue escrito por Neruda antes de la violación que confiesa el poeta, pero son gemelos en la fragmentación y exotización de los cuerpos femeninos. Si "La noche del soldado" tematiza o no exactamente una violación me parece menos relevante que distinguir las continuidades discursivas que comparte con la confesada violación del poeta, pues en ese continuo se revela un Neruda despótico, abusivo, que dista mucho de la imagen popular y romántica con la que ha sido habitualmente consumida su poesía.

\section{Neruda y sus estatuas}

"Su delgadísima cintura, sus plenas caderas, las desbordantes copas de sus senos, la hacían igual a las milenarias esculturas del sur de la India" (Confieso, 134). Así describe Neruda a la sirvienta que viola en Asia, como si fuera una "estatua oscura que caminara" (134). Al representar a su víctima repetidamente como estatua, Neruda prepara el escenario discursivo para narrar, con importantes silencios, la violación que acomete. Pero su sirvienta violada no fue el único cuerpo que Neruda representó como estatua en su trabajo literario. La transformación de mujeres en estatuas es, por el contrario, un tema que impregna fuertemente su poesía. De esta manera, lo que está en la base temática de la violación que confiesa Neruda (transformar a su víctima en una estatua) es también una de las bases temáticas de su poesía amorosa. Neruda describe su violación como el "encuentro" de un "hombre con una estatua" (Confieso, 134). Idea que replica en "La noche del soldado" -"peso con mis brazos cada nueva estatua" (147)- donde la "desubjetivización femenina por parte del narrador" precisa Patricia Vilches, "llega a su clímax" cuando "la mujer se convierte en una estatua" (207). Eisner, por su parte, recalca que "durante el acto de violación" Neruda representa a su víctima como "un pedazo de piedra" (177). Las estatuas se repiten en la confesada violación de Neruda y en el orientalista poema que antecede a este ataque. 
Transformar cuerpos en estatuas para la propia satisfacción sexual no es un tema exclusivo del Neruda de Residencia, pues esta misma idea resuena, por ejemplo, en uno de sus poemas más emblemáticos, el poema XV de sus 20 poemas de amor, donde declara: "me gustas cuando callas porque estas como ausente" (Obras, 94). Estos famosos versos del poeta adquieren otra textura si destacamos que parte del arsenal depredador de Neruda consistió en presentar a la víctima de su violación como si fuera una estatua silenciosa. En todos estos poemas, y en muchos otros, antes y después del ataque a su sirvienta, Neruda transforma los cuerpos de mujeres en estatuas silenciosas, sin subjetividad ni resistencia, como objetos coleccionables o desechables para satisfacer su "hambre sexual" en Asia (Loyola, 295).

Loyola comenta que la "mítica figura femenina" que aparece en los poemas "La noche del soldado", pero también "El joven monarca", "Juntos nosotros", "Diurno doliente" y el "Tango del viudo" de Residencia en la tierra es una figura que "él mismo individualizará más tarde bajo el nombre de Josie Bliss" (Residencia en la tierra, 148). Josie Bliss es el nombre extranjero que le impuso Neruda a su amante de Birmania, o a muchas de ellas 4 . Como precisa Kantor, no hay registros de la existencia de Josie Bliss: "no hay fotos" ni tampoco "evidencia que sugiera que existiera en absoluto" (60)5. Para sumar al misterio, en Santiago de Chile, Neruda usaría "una máscara javanesa", de las muchas de su colección, "para representar su cara" (60). Si Josie Bliss es el nombre y la máscara de las "efímeras mujeres" del poeta en Asia, la sirvienta violada por Neruda es todavía más irrepresentable en su vida y obra. No tiene nombre ni máscaras, solo una presencia silenciosa y espectral.

En el poema "La estatua ciega", de Piedras de Chile, Neruda escribe:

Hice la estatua ciega
que no mirara,
que allí
en la desolada
arena
mantuviera su mole
como mi monumento:
la estatua
ciega (34).

"Mi propia forma" continúa Neruda "copié golpeado a través de los siglos en la piedra" (Piedras de Chile, 34). Estatuas, botellas, máscaras,

\footnotetext{
4 En su novela Tango del viudo, Cristián Barros recrea la relación de Neruda con Josie Bliss en Asia por medio de una violación que es representada en la novela como un romántico ritual de iniciación, y no un ataque sexual: "Josie se tocó los labios con las yemas desnudas, como saliendo de una violación consumada durante un episodio de inocencia" (107). 5 Como dice Kanton "Neruda and generations of critics analyzing his life and work have filled reams of paper with descriptions of Josie as exotic, passionate, animalistic and homicidally jealous" (60). Sin embargo, aclara, "Behind all these descriptions, however, is an absolute void: we lack not just the archival evidence to corroborate this particular version of Josie, but the evidence to suggest that there was ever any Josie at all" (60).
} 
mascarones, dientes de narval, caracolas, mariposas, etc., son parte de un sinnúmero de objetos que el poeta coleccionaba en sus casas, actualmente museos. Objetos que han definido al poeta y su trabajo literario. Celebrar estas colecciones -de objetos y de mujeres, o confundiendo ambas- ha sido uno de los mecanismos de consumo de la poesía de Neruda. En sus estatuas y colecciones se retrata el poeta 6 . Pero su retrato no es solo el de un recolector de cachivaches exóticos de diferentes partes del mundo, sino un retrato mucho más indigesto, como hemos visto.

Tras su estancia en Asia, Neruda consigue otro puesto diplomático del gobierno de Chile, esta vez en Europa. En Madrid, Neruda dice cambiar. Reniega de su pasado asiático y de Residencia en la tierra7. Abraza la política comunitaria y su poesía se aleja de la alienación melancólica de Residencia en la tierra para incluir elementos sociales. Pasa de "Pablo" a "Neruda". La violación de Neruda ha quedado silenciada en esta metamorfosis, arrinconada como un dato de juventud del poeta, como algo pasado y aislable. Las monumentales biografías del poeta en Asia de Loyola, Olivares, Feinstein, Teitelboim, entre muchos otros se han detenido con atención en los años de Neruda en ese continente, como también lo han hecho, pero desde una perspectiva más crítica, los trabajos desde los estudios culturales y de género de Vilches, Sharp, Nagy-Zekmi, entre otras. Pero independientemente de los enfoques en que se ha mostrado al poeta en Asia, la violación que singularizamos en este trabajo ha quedado en las sombras de vida y de la obra de Neruda, pese a que muchos elementos discursivos de la violación se perpetúan en su poesía amorosa y en sus famosas colecciones. Un silencio que ha servido también para destacar, reproducir y consumir un Neruda romántico y comunitario; un Neruda que coloca a las mujeres entre sus "colecciones" y "obras", como dispone la página oficial del poeta.

\section{Neruda: "Colecciones/ Mujeres/ Obra"}

En la página web oficial de Pablo Neruda de la Universidad de Chile, entre los hipervínculos "Colecciones" y "Obras" aparece el hipervínculo "Mujeres": www.neruda.uchile.cl/nerudamujeres. En la lista aparecen Maria Antonieta Hagenaar, Matilde Urrutia, y Delia de Carril8. La mujer violada por Neruda no aparece registrada. Tampoco Josie Bliss, el nombre de la(s)

\footnotetext{
6 Acerca de las colecciones de Neruda hay decenas de estudios. Ver el número especial de la revista Nerudiana (2006) dedicada a las colecciones del poeta, en particular el texto de Alain Sicard, "Neruda: La poética de los objetos". Luis Cárcamo-Huechante específica "la lógica de colección y exposición" (598) que subyace en el poemario de Neruda Maremoto. El trabajo de Cárcamo-Huechante es especialmente iluminador al contrastar las colecciones de Neruda con su poesía, marcada por un deseo patrimonialista y catalogador.

7 Dice Neruda: "Yo también he hablado alguna vez en contra de Residencia en la tierra. Pero lo he hecho pensando, no en la poesía, sino en el clima duramente pesimista que ese libro mío respira. No puedo olvidar que hace pocos años un muchacho de Santiago se suicidó al pie de un árbol, y dejó abierto mi libro en aquel poema titulado "Significa sombras" (Confieso, 384).

8 En las notas a Una casa en la arena Loyola precisa que no hubo "para Delia poemas de amor", "como tampoco lo hubo -no podía haberlo- para la casa, entonces" (146). De esta manera, siguiendo a Loyola, mujeres, casas y colecciones se relacionan y confunden en la poesía de Neruda.
} 
amante(s) asiática(s) del poeta. Pero no es mi interés aumentar la lista de mujeres del poeta, sino llamar la atención a que, precisamente en su página oficial, las "mujeres" de Neruda aparecen entre las "colecciones" y las "obras" del poeta. Una imprudencia, sin duda, pero una imprudencia significativa y frecuente. Las mujeres de Neruda, con o sin nombre, ocupan oficialmente el espacio entre las colecciones de objetos del poeta y su producción literaria que recrea y reproduce precisamente esta voracidad coleccionista de Neruda. Pero con mujeres. Si el dato de la violación de Neruda estuviese menos silenciado, tanto en sus biografías como en la interpretación de su obra, una disposición como la que presenta la página oficial de Neruda de la Universidad de Chile sería impresentable. De estas imprudencias, que suceden solo por medio de silenciar los ángulos más abyectos e indigeribles de la vida y obra del poeta, se ha sedimentado la imagen amorosa y política con la que se consume masivamente la poesía de Neruda. Imagen de consumo nerudiano que este trabajo se ha propuesto revisar, destacando en la violación de Neruda un hecho significativo y descuidado en la vida y obra del poeta, pero sobre todo como una manera de revisar y revisitar la poesía de Neruda y su complejos y siempre cambiante legado.

\section{Obras citadas}

Barros, Cristián (2003): Tango del Viudo. Santiago: Seix Barral, Print.

Cárcamo-Huechante, Luis (2006): "La economía poética del mar: patrimonio y desbordamiento en Maremoto de Neruda. Revista Iberoamericana, 215-216, 587-605. Print.

Despentes, Virginie (2007): Teoría King Kong. Madrid: Melusina, Print.

Eisner, Mark (2018): Neruda. The Poet's Calling. New York: Harper Collins, Print.

Feinstein, Adam (2004): Pablo Neruda. A Passion for a Life. NYC: Bloombury, Print.

Fischer, María Luisa (2008): Neruda: Construcción y legados de una figura cultural. Santiago: Editorial Universitaria, Print.

Roanne Kanton (2014): "Chasing Your (Josie) Bliss: The Troubling Critical Afterlife of Pablo Neruda's Burmese Lover". Transmodernity: Journal of Peripheral Cultural Production of the Luso-Hispanic World 3 (2): 68-81. Print.

Leal, Francisco (2015): "Quise entonces fumar: El opio en César Vallejo y Pablo Neruda: Rutas asiáticas de experimentación". Aisthesis 58: 59-80. Print. . (2017): "Pablo Neruda y el opio (del pueblo). La "metafísica cubierta de amapolas" de Residencia en la tierra". Anales de la literatura chilena 28: 49-62. Print.

Loyola, Hernán (2006): Neruda: La biografía literaria. Santiago: Seix Barral. . 2005: "Introducción y notas". Pablo Neruda. Residencia en la Tierra. Madrid: Cátedra.

Neruda, Pablo (1999): Obras. Vol I, Buenos Aires: Losada, Print. . (2002): Confieso que he vivido. Barcelona: Plaza \& Janés, Print. (1997): Cuadernos de Temuco. Barcelona: Seix Barral, Print. (1957): El hondero entusiasta. Buenos Aires: Losada, Print. (1978): Cartas a Laura. Hugo Montes (ed.). Santiago: Andrés Bello, Print. (2004): Una casa en la arena. Buenos Aires: De bolsillo, Print. 
(1990): Canto general. Enrico Mario Santi (ed.). Madrid: Cátedra, Print. (1961): Piedras de Chile. Buenos Aires: Losada, Print.

(2005): Residencia en la tierra. Hernán Loyola (ed.) Madrid: Cátedra, Print.

(2008): Itinerario de una amistad: Pablo Neruda, Héctor Eandi: Epistolario 1927-1943. Buenos Aires: Corregidor, Print.

Olivares Briones, Edmundo (2000): Pablo Neruda: Los caminos de Oriente. Santiago: LOM, Print.

Reyes, Bernardo (2007): El enigma de Malva Marina: La hija de Pablo Neruda. Santiago: RIL, Print.

Sicard, Alain (2006): "Neruda: La poética de los objetos". Nerudiana 2. 8-14. Print.

Silvia Nagy-Zekmi (2004): "Un licor extremo": Tendencias orientalistas en Neruda". Sophia Austral 9: 31-6. Print.

Teitelboim, Volodia (1991): Neruda. Santiago: Bat Ediciones, Print.

Vilches, Patricia (2008): "'La más bella de Mandalay': Construcciones orientalistas de la feminidad en dos poemas de Neruda". Moros en la costa: Orientalismo en Latinoamérica. Ed. Silvia Nagy-Zekmi. Madrid: Vervuert, 201-217. Print.

Zizek, Slavoj (2011): Living in the End Times. London: Verso, Print. 